\section{Hugo Dante Francisco Ghersi Miranda ${ }^{1}$ Rocío de María Inga Peña}

'Docente del Departamento Académico de Medicina Cirugía y Patología Oral. Facultad de Estomatología. Docente del Departamento Académico de

Bioquímica, Biología Molecular y Farmacología. Facultad de Ciencias y Filosofía.

Universidad Peruana Cayetano Heredia

\section{Correspondencia}

Hugo Ghersi Miranda

Av. Honorio Delgado 430 - Lima 31, Perú

Teléfono (511) 381-1950 (252)

e-mail: hugo.ghersi@upch.pe

Recibido : 27 de noviembre de 2009

Aceptado : 15 de enero de 2010

\title{
Identificación por reacción en cadena de la polimerasa (PCR) de micro- organismos presentes en las infecciones orofaciales odontogé- nicas
}

Ghersi-Miranda HD, Inga-Peña RM. Identificación por reacción en cadena de la polimerasa (PCR) de microorganismos presentes en las infecciones orofaciales odontogénicas. Rev Estomatol Herediana. 2010; 20(1):5-12.

\section{RESUMEN}

El objetivo del presente trabajo fue identificar la presencia de las bacterias, Porphyromonas gingivalis, Tannerella forsythensis y Treponema denticola, denominado complejo rojo; en grupo de tres, en parejas o sola una especie, presentes en las infecciones orofaciales odontogénicas (IOFO), mediante el método de la Reacción de la Polimerasa Reversa (PCR), en las muestras de abscesos de los pacientes que acudieron al Servicio de Odontoestomatologia del Hospital Nacional Cayetano Heredia y a la Clínica Estomatológica Central de la Universidad Peruana Cayetano Heredia. Se obtuvieron 35 muestras, en ninguna de ellas se identificó el complejo bacteriano integrado por $P$. gingivalis, $T$. forsythensis y $T$. denticola. La asociación entre $P$. gingivalis y el T. forsythensis fue la más frecuente con un $5,71 \%$. Al menos uno de los integrantes del complejo bacteriano estuvo presente en el 48,57\% (17 de 35) muestras. La P. gingivalis es la bacteria más prevalente del complejo bacteriano con el $40 \%$ (14 de 35) muestras, seguido de la $T$. forsythensis en un 11,43\% (4 de 35) muestras. La P. gingivalis se identificó en un 42,86\% (6 de 14) muestras del género femenino y 38,1\% (8 de 21) muestras del género femenino. Este estudio ha demostrado por medio de la prueba de PCR, la prevalencia de tres especies bacterianas presentes en las infecciones orofaciales odontogénicas. Aunque la etiología de estos procesos es multifactorial, es muy importante considerar los resultados de este estudio para el manejo racional de las infecciones.

Palabras Clave: REACCIÓN EN CADENA DE LA POLIMERASA / Porphyromonas gingivalis / Treponema denticola.

Identification of bacteria associated with orofacial infections by polimerase chain rection (PCR)

ABSTRACT

The objective of this investigation was to identify the prevalence of Porphyromonas gingivalis, Tannerella forsythensis and Treponema denticola forming the red complex, or as pairs or as single species in odontogenic infections, by mean of the Polymerase Chain Reaction (PCR). The samples were obtained from 35 oral and facial abscesses. In no case the red complex was found. The most frequent association found was $P$. gingivalis and $T$. forsythensis that represented $5.71 \%$. At least, one specie was identified in 17 samples $(48.57 \%)$. P. gingivalis was the most common bacteria representing $40 \%$ (14 out of 35 samples). T. forsythensis was identified in $11.43 \%$ (4 out of 35 samples). T. denticola was the less prevalent with only two cases $(5.71 \%$ ). P. gingivalis was demonstrated in 8 out of 21 males (38\%) and in 6 out of 14 females (42.85\%). This study has demonstrated by PCR the prevalence of three species of odontogenic bacteria as responsible of orofacial infections. Although the etiology of these proccesses is multifactorial, it is very important to consider the results of this study in the rational management of them. This investigation was carried out in the Stomatology Service of Cayetano Heredia National Hospital and in the Oral and Maxillofacial Surgery Service of the School of Dentistry of Cayetano Heredia Peruvian University.

Key words: POLYMERASE CHAIN REACTION / Porphyromonas gingivalis / Treponema denticola.

\section{Introducción}

La compleja microflora oral ha sido reconocida como el agente responsable de las infecciones dentales, orales y faciales (1-3).

La acumulación de bacterias alrededor de los dientes es conocida como placa dental. Muchas infecciones odontogénicas resultan inicialmente de la acumulación de la placa dental, la cual dependiendo de factores como la dieta, saliva, higiene oral y el propio hospedero influyen en la naturaleza y potencial patógeno de esta placa dental $(4,5)$.

Los microambientes de la cavidad oral permiten que un grupo de especies se establezcan en diferentes lugares, en diferentes cantidades y proporciones $(1,4,6)$.

La virulencia de los microorganismos está en relación a los mecanismos de adherencia a las células y tejidos, habilidad para invadir, evasión de los mecanismos de defensa y daño directo o indirecto de los tejidos, originado entre otras razones en las toxinas bacterianas, las cuales precipitan una respuesta inflamatoria $(1,7,8)$.

El estado sistémico del hospedero juega un rol importante en la formación del complejo bacteriano patogénico, el cual es responsable de los procesos infecciosos leves, moderados o severos como las 
infecciones orofaciales odontogénicas (IOFO) (1).

Estas infecciones tienen como principal origen los procesos dentoalveolares, periodontitis y pericoronitis, puntos de partida para la diseminación de las infecciones a las regiones anatómicas adyacentes a los maxilares (2).

Dentro de la microflora oral comensal encontramos aerobios, anaerobios facultativos y estrictos, bacilos, cocos, espiroquetas, gram positivos y negativos. Por diversas razones, dentro de las que tenemos las alteraciones del sistema inmune, un grupo de estas bacterias se transforman en patógenos, siendo reconocidas como responsables de las IOFO $(2,8)$.

Con el transcurrir de los años, Chow en 1978 (7), Kannangara en 1980 (9), Kuriyama et al. en el 2000 (2), Siquiera y Rôças en el 2003 (3), entre otros, han determinando la presencia de ciertos grupos de bacterias en las IOFO, debido esencialmente al desarrollo de nuevos cultivos y las técnicas moleculares, como la PCR $(1,5)$.

La PCR es un método que tiene un amplio uso, uno de ellos es el detectar especies microbianas directamente de las muestras tomadas de distintas zonas del cuerpo $(4,8,10)$. Su sensibilidad, especificidad y rapidez la ha convertido, en los últimos años, en el método de elección utilizado para la determinación bacteriana (7).

En lo que respecta a la detección de microorganismos en las infecciones pulpares y periodontales, la PCR ha contribuido enormemente con la puesta en evidencia de bacterias que no habían sido detectadas con los cultivos. Además se ha podido determinar la presencia de ciertas asociaciones bacterianas que con frecuencia se presentan en determinadas infecciones, tal es el caso del "complejo rojo" descrito por Socranski. Este complejo está integrado por tres bacterias: Tannerella forsythensis, Treponema denticola y Porphyromonas gingivalis, el cual se encuentra especialmente asociado con la enfermedad periodontal agresiva (9).

Actualmente un número de investigaciones utilizando la PCR han detectado algunas bacterias responsables de las periodontopatías y necrosis pulpares con lesiones perirradiculares. Tal es el caso de la P. gingivalis, $T$. forsythensis y $T$. denticola $(5,11)$.

El objetivo del presente estudio fue determinar la presencia de la $P$. gingivalis, $T$. forsythensis y $T$. denticola, grupo de bacterias conocida como complejo rojo en las IOFO por medio de la PCR.

\section{Material y métodos}

Se diseñó un estudio experimental, el cual contó con una muestra no probabilística incidental, constituida por los pacientes que presentaron IOFO y acudieron a la Emergencia o Servicio de Odontoestomatología (SOE) del Hospital Nacional Cayetano Heredia (HNCH) o al Servicio de Cirugía Oral y Maxilofacial (SCOMF) de la Clínica Estomatológica Central (CEC) de la Facultad de Estomatología Roberto Beltrán (FE) de la Universidad Peruana Cayetano Heredia (UPCH), durante los meses de enero del 2005 a mayo del 2006, de donde se obtuvieron las muestras de colección purulenta, que fueron procesadas con PCR.

Los criterios de inclusión fueron: presentar infección oromaxilofacial odontogénica, tener entre 18 y 60 años de edad, no padecer enfermedades sistémicas, evidencia de colección purulenta factible de ser tomada, aceptar y firmar el consentimiento informado.

Las variables evaluadas estuvieron constituidas por el complejo bacteriano denominado "complejo rojo", que es el grupo de especies bacterianas constituída por la Porphyromonas gingivalis, Tannerella forsythensis y Treponema denticola (12), complejo de dos bacterias, que son componentes del "complejo rojo": $P$. gingivalis y $T$. forsythensis; $P$. gingivalis y $T$. denticola y $T$. forsythensis y $T$. denticola y las constituidas por una sola bacteria componente del "complejo rojo": $P$. gingivalis: $404 \mathrm{pb}$, forward AGGCAGCTTGCCA TACTGCG y reverse ACTGTTAGCAACTACC GATGT (4); T. forsythensis: $641 \mathrm{pb}$, forward GCGTATGTAACCTG CCCGCA y reverse TCGTTCAG TGTCAGTTATA CCT (4); $T$. denticola: $316 \mathrm{pb}$, forward TAATACCGAATGTGCTCATTT ACAT y reverse TCAAAG AAGCATTCCCTCTTCTTCTTA (4). Las covaribles evaluadas fueron el género y edad.

En el marco de las consideraciones éticas se obtuvieron las autorizaciones del SCOMF de la CEC de la UPCH, autorización del SOE del HNCH, autorización del Comité de Ética de la UPCH, del HNCH y autorización del Paciente (consentimiento informado).

Para la toma, almacenamiento y procesamiento de las muestras clínicas, se siguió con los protocolos descritos por Siquiera et al. $(8,10,11)$.

Se tomó una muestra del contenido purulento con una jeringa de 20cc y una aguja descartable estéril $\mathrm{N}^{\circ} 18$. Previamente, se procedió a la asepsia de la zona a trabajar con una solución microbicida (yodo-polividona) de uso 
externo, en el caso de piel o digluconato de clorhexidina al $0,12 \%$, en el caso de la cavidad oral.

Luego de realizar la punción en la zona que mostró signos de colección y al llegar con la aguja a la misma, se realizó presión negativa con el émbolo de la jeringa, maniobra que permitió obtener la muestra necesaria para el estudio (aproximadamente 3cc).

La muestra se colocó en un tubo estéril de criopreservación y se almacenó a menos $70^{\circ} \mathrm{C}$ hasta su procesamiento en el laboratorio.

El procesamiento de las muestras de los pacientes y el análisis de los productos fueron realizados en los ambientes de Biología Molecular del Laboratorio de Investigación y Desarrollo (LID) de la UPCH, cuando se completaron 35 muestras.

Las muestras fueron descongeladas colocandolas a $37^{\circ} \mathrm{C}$ por 10 minutos, seguidos de dos lavados con agua bidestilada centrifugando por dos minutos a 2500 g. El sedimento de bacterias se resuspendió en 100uL de agua bidestilada, se hirvió por 10 minutos y colocó en hielo. Los restos de membranas fueron eliminados por centrifugación a $9000 \mathrm{~g}$ por 30 segundos a $4^{\circ} \mathrm{C}$. Se tomó $5 \mathrm{uL}$ del sobrenadante para la reacción de PCR.

Para cada juego de iniciadores se realizó pruebas de estandarización de la reacción: concentración de nucleótidos, oligonucleótidos, $\mathrm{MgCl} 2$, enzima, ADN templado, temperatura y tiempo para cada uno de los pasos, número de ciclos, etc. Para estas pruebas de estandarización se utilizó el ADN purificado de las cepas $P$. gingivalis, $T$. forsythensis y $T$. denticola, los cuales fueron adquiridos de la ATCC.
Los oligonucleótidos utilizados fueron específicos para cada una de las cepas escogidas. Las secuencias de los oligonucleótidos para $T$. forsythensis, $P$. gingivalis y $T$. denticola se tomaron según Rôças et al. (4).

Se utilizaron también, un par de oligonucleótidos universales capaces de amplificar el gen 16S rRNA de casi todas las bacterias, dando un producto de 602 pb. Estos oligonucleótidos utilizados como un control positivo en la reacción de PCR fueron: Forward GATTAGA TACCCTGGTAGTCCAC y Reverse CCCGGGAACGTATTC ACCG.

El análisis de los productos de PCR se hizo mediante electroforesis en gel de agarosa, teñidos con bromuro de etidio y visualizados en el transiluminador de luz ultravioleta. Adicionalmente, para confirmar la identidad de los productos de PCR, se realizó el análisis de la secuencia (con los iniciadores Forward y Reverse) en el equipo secuenciador automático ABI 3100 Avant, en el Instituto de Medicina Tropical Alexander von Humboldt.

Con los resultados obtenidos de la presencia o no de los microorganismos motivo del estudio se obtuvo la proporción y análisis bivariado.

\section{Resultados}

El estudio estuvo conformado por 35 muestras de abscesos originados en IOFO en pacientes entre los periodos comprendidos de enero del 2005 y mayo del 2006.

El uso del método de PCR, basado en un primer universal, permitió identificar la presencia positiva de gérmenes en las 35 muestras analizadas. Luego se realizaron amplificaciones utilizando primers específicos para la determinación de $P$. gingivalis, $T$. forsythensis y T. denticola.

El método molecular utilizado en este estudio permitió determinar que en ningún caso de las 35 muestras analizadas se identificara el complejo rojo constituido por la $P$. gingivalis, T. forsythensis y T. denticola.

En un 8,6\% (3 de 35 casos), se encontró la presencia de dos bacterias del complejo. De ellos, un 5,7\% (2 de 35 muestras) se hallaban juntos $P$. gingivalis y $T$. forsythensis. La pareja constituida por $P$. gingivalis y $T$. denticola se identificó en un 2,9\% (1 de 35 casos) y en ninguna muestra se identificó la pareja de microorganismos constituida por $T$. forsythensis y $T$. denticola.

Al menos un miembro del complejo rojo fue encontrado en el 48,6\% de los casos (17 de 35 casos). En general, la $P$. gingivalis, $T$. forsythensis y $T$. denticola fueron detectados en un $40 \%$ (14 de 35 casos), $11,4 \%$ (4 de 35 casos) y $5,7 \%$ (2 de 35 casos), respectivamente (Fig. 1 y Tabla 1 ).

De las 35 muestras estudiadas, 14 pertenecían al género femenino y 21 al masculino. En cuanto a la distribución según el número de bacterias y el género, se encontró que para el género femenino, el $42,9 \%$ (6 de 14) muestras presentaba una bacteria; en el 7,1\% (1 de 14) de las muestras existía la asociación de dos bacterias. En el género masculino se identificó en un $38,1 \%$ (8 de 21) muestras solo una bacteria, 9,5\% (2 de 21) dos bacterias juntas. (Tabla 2).

En un 40\% (14 de 35) del total de las muestras se encontró resultados positivos a la presencia de P. gingivalis, la cual se distribuyó de acuerdo al género de la siguiente forma: $42,9 \%$ (6 de 14) en el femenino y $38,1 \%$ (8 de 21) en el 
masculino. En el 11,4\% (4 de 35) de las muestras se demostró la presencia de $T$. forsythensis, representando un 14,3\% (2 de 14) en el género femenino y 9,5\% (2 de 21) en el masculino. El T. denticola solo se identificó en el género masculino en un 9,5\% (2 de 21). (Tabla 3).

Solo tres muestras $(8,6 \%)$ son positivas a la presencia de dos bacterias juntas. La pareja de $P$. gingivalis y T. Forsythensis se identificó en un 5,7\% (2 de 35) compartidas una para cada género. La asociación de $P$. gingivalis y $T$. denticola se presentó en un solo caso y fue en el género masculino representando un 4,8\% (1 de 21), y un el 2,9\% del total de las muestras estudiadas.

La media de la edad del género femenino que presentó la $P$. gingivalis fue de 30,5 años (22 a 39 años) y 31,5 años (23 a 30 años) para los varones. La T. forsythensis que se identificó en el género femenino presentó una media de 36 años (22 a 50 años) y de 33,5 años (21 a 46 años) para los varones. En solo dos casos, (ambos varones de 21 años) se encontró T.denticola y

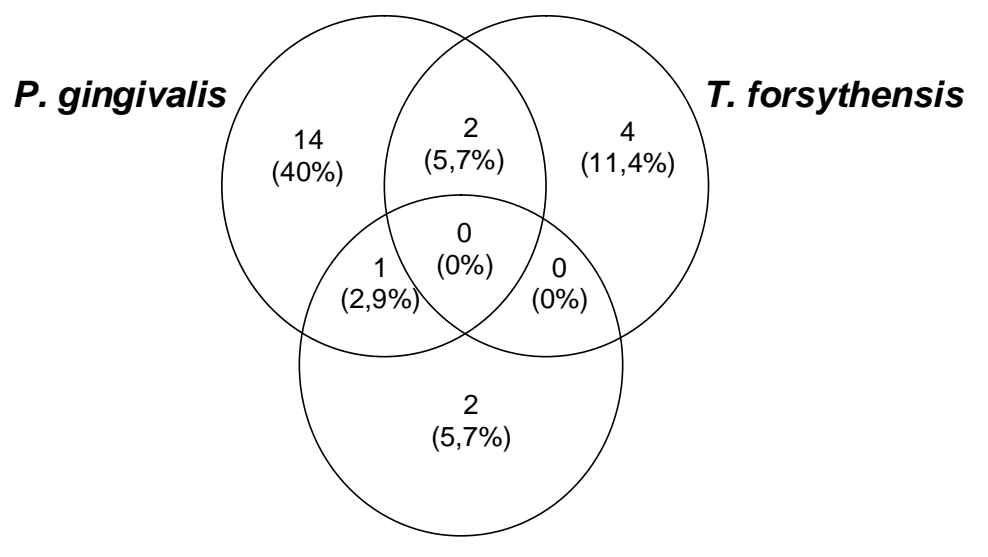

T. denticola

Fig. 1. Prevalencia de las bacterias identificadas por PCR en las IOFO en la Clínica Dental de la UPCH y el HNCH de enero del 2005 a mayo del 2006.

Tabla 1. Prevalencia de las bacterias identificadas por PCR en las IOFO en la Clínica Dental de la UPCH y el HNCH de enero del 2005 a mayo del 2006.

\begin{tabular}{lrr}
\hline Bacteria & $\mathrm{n}$ & $(\%)$ \\
\hline$P$. gingivalis & 14 & $(40,0)$ \\
$T$. forsythensis & 4 & $(11,4)$ \\
T. denticola & 2 & $(5,7)$ \\
$P$. gingivalis /T. forsythensis & 2 & $(5,7)$ \\
$P$. gingivalis / T. denticola & 1 & $(2,9)$ \\
T. forsythensis /T. denticola & 0 & $(0,0)$ \\
$P$. gingivalis / T. forsythensis / T. denticola & 0 & $(0,0)$ \\
\hline $\mathrm{N}=35$ &
\end{tabular}

Tabla 2. Número y porcentaje de bacterias presentes según género, en las IOFO en la Clínica Dental de la UPCH y el HNCH de enero del 2005 a mayo del 2006.

\begin{tabular}{|c|c|c|c|}
\hline Bacterias & Femenino $(n=14)$ & Masculino $(n=21)$ & Total $(\mathrm{N}=35)$ \\
\hline presentes & n $(\%)$ & $(\%)$ & $(\%)$ \\
\hline Una & $6(42,9)$ & $8(38,1)$ & $14(40,0)$ \\
\hline Dos & $(7,1)$ & $(9,5)$ & $(8,6)$ \\
\hline Total & $7 \quad(50,0)$ & $10(47,6)$ & $17(48,6)$ \\
\hline
\end{tabular}

la media fue de 21 años. (Tabla 4).

\section{Discusión}

Este estudio, pionero en aplicar la PCR en las muestras obtenidas de pacientes que presentaban IOFO en nuestro medio, busca determinar si existe la presencia de $P$. gingivalis, T. forsythensis y $T$. denticola, independientemente o en asociaciones de dos o tres bacterias.

La presencia de estas bacterias y sus características patogénicas han sido descritas por diversos autores, además de encontrar una alta asociación con las infecciones periodontales severas $(3,11)$.

Rôças et al. (4) en su estudio reportaron que las especies microbianas que se investigaron en nuestro estudio poseen, al menos in vitro, factores virulentos que pueden estar incluidos en la generación de daño tisular con la consecuente inflamación e infección.

La $P$. gingivalis es un importante patógeno de la enfermedad periodontal, que en recientes estudios moleculares ha demostrado potencial patógeno en las infecciones pulpares. En el estudio de Rôças et al. (4) se presentó en un $30 \%$ de los casos y además sugiere se realicen estudios exhaustivos de su capacidad virulenta. Dentro de los posibles causas que podrían explicar su virulencia, relacionados con el daño tisular, se encuentran: la lipopolisacaridasa,fimbriae, cápsula, lipoproteínas, proteinasas, colagenasa, fosfolipasa, aminopeptidasas, fibrinolisina, fosfatasa alcalina y ácida, ADNasa y ARNasa, hialuronidasa, condroitin sulfatasa, hemolisinas y metabolitos citotóxicos: sulfato de hidrógeno, metilmercaptán, dimetil bisulfato, butirato, propionato, indol y amonio.

La patogenicidad de la $P$. gingivalis puede variar significativa- 
Tabla 3. Distribución de las bacterias identificadas de acuerdo al género, en las IOFO en la Clínica Dental de la UPCH y el HNCH de enero del 2005 a mayo del 2006.

\begin{tabular}{lcccccc}
\hline & \multicolumn{2}{l}{ Femenino $(\mathrm{n}=14)$} & \multicolumn{2}{c}{ Masculino $(\mathrm{n}=21)$} & \multicolumn{2}{l}{ Total $(\mathrm{N}=35)$} \\
Bacteria & $\mathrm{n}$ & $(\%)$ & $\mathrm{n}$ & $(\%)$ & \multicolumn{1}{c}{$\mathrm{N}$} & $(\%)$ \\
\hline P. gingivalis & 6 & $(42,9)$ & 8 & $(38,1)$ & 14 & $(40,0)$ \\
T. forsythensis & 2 & $(14,2)$ & 2 & $(9,5)$ & 4 & $(11,4)$ \\
T. denticola & 0 & $(0,0)$ & 2 & $(9,5)$ & 2 & $(5,7)$ \\
Total & 8 & $(57,1)$ & 12 & $(57,1)$ & 20 & $(57,1)$ \\
\hline
\end{tabular}

Tabla 4. Presencia de las bacterias de acuerdo al género y promedio de edades en las IOFO en la Clínica Dental de la UPCH y el HNCH de enero del 2005 a mayo del 2006.

\begin{tabular}{llll}
\hline Bacteria & $\begin{array}{l}\text { Femenino } \\
\text { Prom. edad }\end{array}$ & $\begin{array}{l}\text { Masculino } \\
\text { Prom. edad }\end{array}$ & $\begin{array}{l}\text { Total } \\
\text { Prom. edad }\end{array}$ \\
\hline P. gingivalis & 30,5 años (22-39) & 31,5 años (23.30) & 31 años \\
T. forsythensis & 36 años (22-50) & 33,5 años (22-50) & 34-75 años \\
T. denticola & ------ & 21 años & 21 años \\
\hline
\end{tabular}

mente dentro de las muestras; algunas veces en cultivos puros y otras veces en asociación con otras bacterias (4).

Otro microorganismo recientemente detectado en las infecciones pulpares por medio de la tecnología molecular es $T$. forsythensis (antes $B$. forsythus). En el estudio de Rôças et al. (4) fue encontrado en $40 \%$ de los casos. Dentro de los factores probables de su virulencia se mencionan: gingivapaína (enzima parecida a la tripsina), fosfatasa alcalina, fosfatasa ácida, acetato, propionato, butirato isovalerato y fenilacetato. La $T$. forsythensis es usualmente patógena cuando se encuentra en infecciones mixtas.

La especie $T$. denticola ha demostrado poseer propiedades capaces para inducir daño tisular, como por ejemplo: adherencia a las células del hospedero, gran actividad proteolítica y citotoxicidad. Estos factores virulentos incluyen proteínas con actividad citotóxica (proteína de superficie), complejo de proteasa similar a la quimiotripsina, otras enzimas hidrolíticas y proteolíticas asociadas a las membranas tales como: lipopolisacaridasa, lipoproteínas, de estas.

La elección de la PCR como prueba a utilizar en este estudio, se originó en la revisión de la literatura, donde se manifiesta claramente las ventajas que esta técnica presenta en comparación con el método de cultivo.

Los métodos moleculares, particularmente la PCR, proveen un significativo conocimiento adicional con respecto a la composición de la microflora, porque permiten detectar especies bacterianas difíciles de cultivar o que tienen comportamientos fenotípicamente divergentes (3). Asimismo provee, resultados superiores al de los cultivos y son al menos 10 a 100 veces más sensible que otros métodos de identificación microbiológica (8).

La PCR es utilizada directamente con las muestras tomadas, sin la necesidad de realizar cultivos para la identificación (14). Existen numerosos estudios en las áreas de endodoncia y periodoncia, donde se han comparado los cultivos microbiológicos y la PCR, con el fin de detectar bacterias específicas, llegándose al consenso que la detección bacteriana por PCR es más sensible y confiable que los métodos de cultivo (15).

En los últimos reportes presentados por el grupo de Siqueira y Rôças $(3,8,10,11)$, Socransky et al. (12), muestran claramente el gran aporte de esta técnica, al poderse apreciar bacterias anteriormente no identificadas como la $P$. gingivalis, T. forsythensis, $T$ denticola, $S$. constellatus, $P$. nigrescens, $T$. socranskii, entre otras, en las infecciones periodontales $y$ endodónticas, información muy valiosa y que en los reportes basados en cultivos no eran mencionadas. Por ejemplo, en el estudio de Kuriyama et al. (2) donde se estudian 
(con cultivos) muestras de abscesos odontogénicos de 163 pacientes, no se aisla ninguna de las bacterias antes mencionadas. Lo mismo sucede con Aderhold et al. (18), Chow et al. (7), Heimdahl et al. (19), Von Konow et al. (20), Oguntebi (17), Sakamoto et al. (21), Kannangara et al. (9).

Chow et al. (7) y Sabiston et al. (16) mencionan que la mayoría de las infecciones dentales son causadas por bacterias anaerobias. En sus experiencias, al menos 2 a 4 bacterias anaerobias fueron encontradas en la mayoría de las infecciones odontogénicas.

Es importante realizar estudios para aclarar el rol de cada microorganismo y sus asociaciones, con la finalidad de conocer el comportamiento de cada uno de éstos patógenos en la ocurrencia y pronóstico de las infecciones odontogénicas.

En nuestro estudio no hemos encontrado la presencia de $P$. gingivalis, $T$. forsythensis y $T$. denticola denominado complejo rojo, en ninguna de las 35 muestras obtenidas. Rôças et al. (4) obtuvieron este complejo bacteriano en un $5 \%$ de los 20 casos de infecciones de conductos radiculares que estudió y en otro estudio específico (también realizado por su equipo), para determinar la presencia del complejo rojo en cincuenta infecciones endodónticas, identificaron una presencia del 8\% (4 de 50). Estos hallazgos no coinciden con los encontrados por Socransky et al. (12) en las enfermedades periodontales. Estas diferencias pueden deberse a las diferencias naturales, como los microambientes, sistemas de conductos radiculares y bolsas periodontales (11).

En este estudio se coincidió con los resultados encontrados sobre infecciones endodónticas, más no en infecciones periodontales. La principal etiología de las IOFO son periodontales (2). El gran número de bacterias inmersas en estas infecciones (demostrado con la prueba con el oligonucleótido universal) nos hace pensar que otras especies o grupos deben estar jugando roles más importantes que las integrantes del complejo rojo.

Sin embargo, la identificación en el estudio de tres muestras con dos bacterias juntas, resultado que representa el 8,6\%, es un indicador que las infecciones están compuestas por grupos mixtos de bacterias en lo que a microbiología se refiere, más aún si se toma como soporte que las 35 muestras fueron positivas a la identificación con el primer universal, el cual nos permite determinar la presencia de bacterias en las muestras, pero sin identificarlas.

Las dos parejas identificadas estaban conformadas por $P$. gingivalis y $T$. forsythensis en 5,7\% (2 de 35) y $P$. gingivalis y $T$. denticola 2,9\% (1 de 35). La presencia del $P$. gingivalis en asociación con otras bacterias estan descritas frecuentemente en los estudios anteriormente mencionados $(4,11,16)$.

Un 48,6\% (17 de 35) de las muestras fueron positivas a alguna bacteria del complejo estudiado, este resultado coincide con los estudios realizados con PCR, donde existe la presencia de alguna de estas bacterias en las IOFO.

Un hallazgo interesante es del $40 \%$ (14 de 35) de las muestras positivas solo para $P$. gingivalis, resultado que se asemeja al encontrado por Rôças et al. $(4,11)$ y Siquiera et al. (10) Es importante mencionar que algunos estudios fueron realizados en infecciones endodónticas y otro, el de Siquiera et al. (6), en una muestra de 27 abscesos periradiculares, donde se encontró que la presencia de la P. gingivalis es del $29,6 \%$, resultado similar a los dos anteriores.

Refiriéndonos a la $T$. forsythensis, solo se ha detectado su presencia en un 11,4\% (4 de 35 muestras), resultados opuestos a los encontrados por Siquiera et al. (10) $29,6 \%$ y Rôças et al. $(4,11)(26 \%$ y $40 \%$ ) en sus dos estudios respectivamente. Cabe resaltar que la presencia de esta bacteria se ha reportado recientemente, desde que se han aplicado los métodos moleculares.

El T. denticola solo fue identificado en un 5,7\% (2 de 35 muestras). Este resultado concuerda con el encontrado por Siquiera et al. (3) en su estudio de 27 abscesos agudos perirradiculares, donde halló un $3,7 \%$ ( 1 de 27 casos). Si se lo compara con los resultados encontrados por Rôças et al. $(4,11)$ en sus dos estudios relacionados con infecciones endodónticas, 50\% (10 de 20) y 44\% (22 de 50), respectivamente, se va apreciar una diferencia significativa, lo cual permite postular que el $T$. denticola está presente en un alto porcentaje de las infecciones pulpares, mas no así cuando la infección o la colección purulenta invade otras zonas anatómicas más profundas.

La identificación de una sola bacteria con relación al género fue de 42,9 (6 de14) y 38,1\% (8 de 21) para el género femenino $y$ masculino, respectivamente, y, en el caso de grupos de solo dos bacterias, se identificó un 7,1\% (1 de 14) en el género femenino y 9,5\% (2 de 21) en el masculino.

En el género femenino se encontró un 57,1\% (8 de 14) de muestras que solo fueron positivas 
para una de las tres bacterias estudiadas y en los varones un $57,1 \%$ (12 de 21).

La edad promedio en que se presentó la $P$. gingivalis en relación al género femenino fue de 36 años (22 a 50 años) y de 33,5 años (21 a 46 años) en varones. El promedio edad de presentación de la $T$. forsythensis en el género femenino fue de 30,5 años (22 a 39 años) y 31,5 años (23 a 30 años) para los varones. Esta información no se puede comparar por no contarse con investigaciones similares.

El número de muestras procesadas en este estudio, limita un análisis estadístico más riguroso, pero como se puede apreciar, las IOFO no son patologías que se presenten con mucha frecuencia y si además se añaden los criterios de selección, se limita aún más el tamaño de la muestra. Estas son algunas de las razones más importantes del por qué del tiempo transcurrido en la recopilación de las muestras. La falta de estudios de similares características limita una más nutrida discusión, pero a la vez estimula al despliegue de nuevos trabajos en esta línea de investigación.

Es importante conocer que las IOFO son patologías que, a pesar de su baja incidencia en el Perú, no dejan de ser una enfermedad muy relacionada con la pobreza, una de las principales características del país. Como consecuencia de ello, la nutrición de nuestra población es deficiente, repercutiendo directamente en el estado sistémico del paciente. La microflora en cuanto a su cantidad, tipo, calidad y comportamiento asociados a otros factores más, juegan un papel preponderante en la aparición de las IOFO.

$$
\text { Los cirujanos orales y }
$$

maxilofaciales que enfrentan este tipo de patología se encuentran con ciertas limitaciones en cuanto a algunas interrogantes que nacen al diagnosticar y tratar estos casos. Las principales dudas radican en determinar las variables que en conjunto pueden generar tan magno problema en el paciente, el que puede fallecer por esta causa, más aún si no es manejado pertinentemente.

Dentro de las variables principales se encuentran: el estado sistémico y la microflora, en este caso se eligió identificar parte de la microflora que pudo estar presente en las muestra obtenidas de las IOFO que padecieron un grupo de pacientes atendidos en dos centros de referencia ubicados en el cono norte de la ciudad de Lima.

Cuando se dice "parte de la microflora" es porque se tiene una gran limitación en poder contar con los materiales necesarios para investigar un número mayor de bacterias y, mejor aún, cuantificarlas luego de detectarlas.

Es importante identificarlas y luego cuantificarlas, porque así se puede determinar si tienen o no el potencial de patogenicidad necesario para causar estas infecciones cuando se presentan especies solas o en complejos bacterianos.

\section{Conclusiones}

- No se identificó el complejo bacteriano integrado por $P$. gingivalis, $T$. forsythensis y $T$. denticola en ninguna de las muestras.

- La asociación entre $P$. gingivalis y el $T$. forsythensis fue la más frecuente con un 5,7\%.

- Al menos uno de los integrantes del complejo bacteriano está presente en el 48,6\% de los casos.

- La P. gingivalis es la bacteria más prevalente con el $40 \%$, seguido de la $T$. forsythensis en un $11,4 \%$ de los casos.

- La P. gingivalis se identificó en un $42,9 \%$ de las muestras del género femenino y un $38,1 \%$ en las del masculino.

\section{Referencias bibliográficas}

1. Moenning JE, Nelson CL, Kohler RB. The microbiology and chemotherapy of odontogenic infections. J Oral Maxillofac Surg. 1989; 47(9):976-85.

2. Kuriyama $\mathrm{T}$, Karasawa $\mathrm{T}$, Nakagawa K, Saiki Y, Yamamoto E, Nakamura S. Bacteriologic features and antimicrobial susceptibility in isolates from orofacial odontogenic infections. Oral Surg Oral Med Oral Pathol Oral Radiol Endod. 2000; 90(5):600-8.

3. Siqueira JF Jr, Rôças IN. PCR methodology as a valuable tool for identification of endodontic pathogens. J Dent. 2003; 31(5):333-9.

4. Rôças IN, Siqueira JF Jr, Andrade AF, Uzeda M. Identification of selected putative oral pathogens in primary root canal infections associated with symptoms. Anaerobe. 2002; 8(4):200-8.

5. Rolph HJ, Lennon A, Riggio MP, Saunders WP, MacKenzie D, Coldero L, Bagg J. Molecular identification of microorganisms from endodontic infections. J Clin Microbiol. 2001; 39(9):3282-9.

6. Siqueira JF Jr, Rôças IN, Souto $\mathrm{R}$, Uzeda M, Colombo AP. Microbiological evaluation of acute periradicular abscesses by DNA-DNA hybridization. Oral Surg Oral Med Oral Pathol Oral Radiol Endod. 2001; 92(4):4517.

7. Chow AW, Roser SM, Brady FA. 
Orofacial odontogenic infections. Ann Intern Med. 1978; 88(3):392-402.

8. Rôças IN, Siqueira JF Jr, Andrade AF, Uzeda M. Oral treponemes in primary root canal infections as detected by nested PCR. Int Endod J. 2003; 36(1):20-6.

9. Kannangara W, Thadepalli H and McQuirter J. Bacteriology and treatment of dental infections. Oral Surg Oral Med Oral Pathol 1980; 50(2): 103-9.

10. Siqueira JF Jr, Rôças IN, Andrade AF, de Uzeda $\mathrm{M}$. Peptostreptococcus micros in primary endodontic infections as detected by $16 S$ rDNA-based polymerase chain reaction. J Endod. 2003; 29(2):111-3.

11. Rôças IN, Siqueira JF Jr, Santos KR, Coelho AM. "Red complex" (Bacteroides forsythus, Porphyromonas gingivalis, and Treponema denticola) in endodontic infections: a molecular approach. Oral Surg Oral Med Oral Pathol Oral Radiol Endod. 2001; 91(4):468-71.

12. Socransky SS, Haffajee AD,
Cugini MA, Smith C, Kent RL Jr. Microbial complexes in subgingival plaque. J Clin Periodontol. 1998; 25(2):134-44.

13. Takemoto T, Kurihara H, Dahlen G. Characterization of Bacteroides forsythus isolates. J Clin Microbiol. 1997; 35(6):137881.

14. Machado de Oliveira JC, Siqueira JF Jr, Alves GB, Hirata $\mathrm{R}$ Jr, Andrade AF. Detection of Porphyromonas endodontalis in infected root canals by $16 \mathrm{~S}$ rRNA gene-directed polymerase chain reaction. J Endod. 2000; 26(12):729-32.

15. Martin FE, Nadkarni MA, Jacques NA, Hunter N. Quantitative microbiological study of human carious dentine by culture and real-time PCR: association of anaerobes with histopathological changes in chronic pulpitis. J Clin Microbiol. 2002; 40(5):1698-704.

16.Sabiston CB Jr, Grigsby WR, Segerstrom N. Bacterial study of pyogenic infections of dental origin. Oral Surg Oral Med Oral Pathol. 1976; 41(4):430-5.
17. Oguntebi B, Slee AM, Tanzer JM, Langeland K. Predominant microflora associated with human dental periapical abscesses. J Clin Microbiol. 1982; 15(5):964-66.

18. Aderhold L, Knothe H, Frenkel G. The bacteriology of dentogenous pyogenic infections. Oral Surg Oral Med Oral Pathol. 1981; 52(6):583-7.

19. Heimdahl A, von Konow L, Satoh T, Nord CE. Clinical appearance of orofacial infections of odontogenic origin in relation to microbiological findings. J Clin Microbiol. 1985; 22(2):299-302.

20. von Konow L, Köndell PA, Nord CE, Heimdahl A. Clindamycin versus phenoxymethylpenicillin in the treatment of acute orofacial infections. Eur J Clin Microbiol Infect Dis. 1992; 11(12):1129-35.

21. Sakamoto H, Kato H, Sato T, Sasaki J. Semiquantitative bacteriology of closed odontogenic abscesses. Bull Tokyo Dent Coll. 1998; 39(2):103-7. 